W. Pusz, W. Kita, and R. Weber - Microhabitat influences the occurrence of airborne fungi in copper mine in Poland. Journal of Cave and Karst Studies, v. 76, no. 1, p. 14-19. DOI: 10.4311/2013MB0101

\title{
MICROHABITAT INFLUENCES THE OCCURRENCE OF AIRBORNE FUNGI IN COPPER MINE IN POLAND
}

\author{
Wojciech Pusz', WŁodzimierz Kita', and Ryszard Weber²
}

\begin{abstract}
From January to April 2012 we studied the occurrence of air-borne fungi in the Lubin mining site, property of KGHM Polska Miedź SA. The research was conducted in three copper-mining shafts: Bolesław, Lubin Zachodni (Lubin West shaft), and Lubin Główny (Lubin Main shaft) at about 610 to 850 meters below ground level. Air samples were collected between 6 and 9 a.m. using the impact method (Air Ideal 3P Sampler) onto Potato Dextrose Agar. The volume of air sampled for each agar plate was 50 liters. We found twenty-seven fungal species, the most numerous being Penicillium notatum, P. urticae, and Aspergillus flavus. As the application of log-linear and correspondence analyses have shown, the population of fungi varied considerably among the copper mine shafts or shaft parts. P. notatum and P. urticae were found to be the best adapted to grow in copper-mine conditions. The significant interaction among the shafts and the sample collection sites suggests a substantial microclimate influence on the population-size variations of studied fungal species in each shaft. The fungal-spore concentration in the majority of the shafts of this copper mine does not present a health risk to the mine workers. But it is enhanced in some portions of the mine, so it may constitute a health hazard locally.
\end{abstract}

\section{INTRODUCTION}

The copper-ore deposits near the town of Lubin were discovered during a geological survey in 1957. The construction of the Lubin copper-mining site began in 1960, laying a foundation for what later became the Copper Mining and Smelting Industrial Complex (KGHM). In the Lubin facility copper is mined at about 610 to 850 meters below ground level, and the operations cover approximately $160 \mathrm{~km}^{2}$ of surface.

The microclimate in some Lubin mine shafts and galleries displays features similar to the tropical rainforest climate. At some points the temperatures rise to $33{ }^{\circ} \mathrm{C}$ and the relative humidity exceeds $90 \%$. These conditions, with the presence of organic substances, creates a fairly favorable growth environment for microscopic fungi, which can be found on any material used in the mining process, especially on timber and all types of organic waste, as well as on insulators, rubber surfaces, or machinery tires (Piontek and Bednar, 2010). The miners going down to work bring fungi into the mine. The research conducted by Grzyb and Fraczek (2010) in spa rooms of the underground salt mine in Bochnia has shown that the number of colony forming units obtained before the staff and clients entered the spa was considerably smaller than the CFU value in high tourist season.

The growth of fungi in the KGHM mine galleries and excavations is considerable and produces a great number of spores that spread through the ventilation system. Frequent air changes, which are characteristic to the microclimate of the KGHM Lubin mining site, result in significant variations of the number of CFU present in the studied air samples. Some airborne fungal species
(Aspergillus spp., Penicillium spp., Cladosporium spp.) that occur in the mine excavations and galleries could cause allergies and fungal infections in some exposed workers (Heppleston et al., 1949; Gamboa et al., 1996; Obtułowicz, 2006; Cabral, 2010). The official limits of airborne fungalspore concentration indoors used in Poland as safety standards (Polish Norm, 1989a, b, and 2007) do not apply to mine excavations or galleries. Most of the fungal spores found in the copper-mine air samples or on organic material such as timber safety structures built in the galleries produce mycotoxins. These can cause various diseases when introduced into the human body (Rusca et al., 2008; Ogórek et al., 2013). The aim of our research was to determine which species of airborne fungi occur in the copper mine and to identify their CFU concentrations.

\section{Materials And Methods}

This study was performed from January to April 2012 in the Lubin mining facilities, owned by KGHM Polska Miedź SA. The measurements were taken in three shafts: Bolesław shaft, Lubin Zachodni (Lubin West shaft), and Lubin Główny (Lubin Main shaft), at about 610 to 850 meters below ground level. The samples were collected between 6 and 9 a.m. At this time of day four hundred miners work in the Lubin West shaft and the Lubin Main shaft, while approximately nine hundred miners work in the Bolesław shaft. We used the impact method and the Air

\footnotetext{
${ }^{1}$ Wrocław University of Environmental and Life Sciences, Department of Plant Protection, Division of Phytopathology and Mycology, pl. Grunwaldzki 24a, 50-363 Wrocław, Poland, wojciech.pusz@up.wroc.pl

${ }^{2}$ Institute of Soil Science and Plant Cultivation, State Research Institute in Pulawy; Department of Weed Science and Tillage Systems in Wrocław
} 
W. Pusz, W. KitA, And R. Weber

Table 1. Test of marginal and partial associations between the types and sections of the mine shafts in KGHM, and the abundance of fungal species.

\begin{tabular}{lccc}
\hline Factor & Degrees of Freedom & Chi-squared (Partial Association) $^{\mathrm{a}}$ & Chi-squared (Marginal Association) $^{\mathrm{a}}$ \\
\hline Type of shaft (1) & 2 & 31477.4 & 31477.4 \\
Part of shaft (2) & 5 & 77662.7 & 77662.7 \\
Fungal species (3) & 10 & 114938.1 & 114938.1 \\
$1 \times 2$ & 10 & 32381.5 & 38421.0 \\
$1 \times 3$ & 20 & 24606.8 & 30646.2 \\
$2 \times 3$ & 50 & 24700.4 & 30739.8 \\
\hline
\end{tabular}

${ }^{a}$ In all cases, the $p$ values is highly significant $(p \leq 0.01)$.

Ideal 3P sampler to analyze the fungal load using PDA (Potato Dextrose Agar) plates manufactured by Biocorp. The volume of air sampled for each plate was 50 liters. The measurements at each site were performed three times, and the impactor was held at $1.5 \mathrm{~m}$ above the ground. The PDA plates were incubated for seven days at room temperature $\left(22{ }^{\circ} \mathrm{C}\right)$. After incubation, the number of visible colonies was determined, and the fungi were identified into species according to their morphology. The number of colony forming units (CFU) was determined per $1000 \mathrm{~L}\left(1 \mathrm{~m}^{3}\right)$ of air. The number of fungal colonies grown on one plate per $1 \mathrm{~m}^{3}$ was determined of air using the formula $X=(a \times 1000) / V$, where $a$ is the total number of airborne fungal colonies grown on one plate after sampling from the atmosphere and $V$ is the collected air volume in liters.

The log-linear and correspondence analyses were performed in order to investigate the relationship among the shafts and the variations in the number of CFU for selected fungal species.

Log-linear analysis is used to examine quantity variations in cross-tabulation. It is also helpful in performing an analysis of variance if no individual observations can be made at any level of the objects experimented on (null values). The log-linear analysis applied to this study is based on Goodman (1978). All significant deviations of the observed quantities from the expected quantities indicate an interaction between the analyzed variables. After a logarithmic transformation of the expected values, the model is expressed as a linear model that, in its most simple form, can be expressed as follows:

$$
\ln \left(E_{i j}\right)=M+\lambda_{i}^{X}+\lambda_{j}^{Y}+\lambda_{i j}^{X Y}
$$

where $E_{i j}$ are the expected values, $M$ is the overall mean of the expected values based on equal counts in each cell, $\lambda_{i}^{X}$ is the effect of the $i^{\text {th }}$ value of variable $X, \lambda_{j}^{Y}$ is the effect of the $j^{\text {th }}$ value of variable $Y$, and $\lambda_{i j}^{X Y}$ is the interaction effect of the $i^{\text {th }}$ value of variable $X$ and $j^{\text {th }}$ value of variable $Y$.

The log-linear model allows us to test the null hypothesis, in which there is no relationship between two or more of the analyzed variables. After eliminating nonsignificant interactions, the model can also be used to investigate the influence of specific factors on the variation of the studied populations. In order to assess a testing model that would be optimal for the specific factors of this experiment, the chi-squared test was calculated for main effects, then the extended log-linear models were tested, taking into account the second- and third-order interactions between the studied factors. An iterative procedure was applied to fit the model to the observed frequencies. The iterative algorithm was stopped when the fit and the observed marginal distributions converged with a ratio of 0.01 .

In practice, these procedures usually eliminate insignificant interactions between observed variables from the model. In the next section, we discuss the structure of relationships between the shafts and the observed population size of each analyzed fungal species. The discussion is based on correspondence analysis, popularized by Hill (1974) and often also referred to as reciprocal averaging, homogeneity analysis, dual scaling, or canonical analysis of contingency tables. The analysis visualizes the associations among a set of points in a two-, or (maximum) threedimensional space. Mapping the variations among the identified fungal species also allows for presenting the variability of the analyzed factors.

\section{RESULTS}

Analyzing the air in the copper-mine galleries, we identified twenty-seven airborne fungal species with Penicillium notatum, $P$. urticae, and Aspergillus flavus being the most numerous. The significance assessment of main effects and interactions among the factors of this experiment is presented in Table 1.

The influence of the shaft and the sample collection point on the population size of fungal species was described in a statistical model, fitted and optimized by calculating the chi-squared test values for the main effects and the interactions between each of the factors in this experiment. The model statistics for second-order interactions displayed considerable values. At $p<0.01$ we rejected the hypothesis of no relationship between the population size of each fungal species and the specific shaft or sample collection point. Significant interactions between the fungal 
Table 2. Fungal population sizes in various parts of Bolesław shaft $\left(\mathrm{CFU} / \mathrm{m}^{3}\right)$.

\begin{tabular}{lrrrrrrr}
\hline & \multicolumn{7}{c}{ Parts of Bolesław Shaft } \\
\cline { 2 - 8 } Fungi & $\begin{array}{c}\text { Timber } \\
\text { Storage }\end{array}$ & $\begin{array}{c}\text { Maintenance } \\
\text { Chamber }\end{array}$ & $\begin{array}{c}\text { Dump } \\
\text { Hopper }\end{array}$ & $\begin{array}{c}\text { Gob } \\
\text { Fence }\end{array}$ & $\begin{array}{c}\text { Machine } \\
\text { Chamber }\end{array}$ & Mouth & Total \\
\hline Aspergillus flavus & 7560 & 220 & 760 & 240 & 680 & 1 & 9461 \\
Aspergillus niger & 0 & 40 & 0 & 0 & 0 & 1 & 41 \\
Botrytis cinerea & 0 & 0 & 240 & 1 & 12 & 0 & 253 \\
Penicillium citrinum & 1 & 1 & 0 & 0 & 1 & 40 & 43 \\
Penicillium commune & 0 & 0 & 92 & 1840 & 0 & 0 & 1932 \\
Penicillium expansum & 0 & 0 & 1 & 1 & 0 & 1 & 3 \\
Penicillium luteum & 0 & 340 & 1 & 12 & 1 & 1 & 355 \\
Penicillium notatum & 8528 & 240 & 6520 & 9560 & 326 & 60 & 25234 \\
Penicillium urticae & 4420 & 380 & 440 & 1360 & 240 & 1 & 6841 \\
Penicillium vermiculatum & 1 & 1 & 0 & 0 & 1 & 0 & 3 \\
Penicillium waksmani & 960 & 1 & 420 & 680 & 80 & 0 & 2141 \\
Total & 21470 & 1223 & 8474 & 13694 & 1341 & 105 & 46307 \\
\hline
\end{tabular}

population sizes and the type of shaft, as well as between the sample collection point and the number of identified fungal species, point to a considerable variation within the fungal population that depends on the factors examined during the experiment. As shown in Tables 2, 3, and 4, many more fungal species were identified in Bolesław shaft than in Lubin Main shaft. The P. notatum species occurred mostly in the Bolesław and Lubin West shafts. The Lubin Main shaft was colonized mostly by $P$. urticae, $P$. waksmani, and $P$. commune. Probably the climate conditions of the Lubin West shaft were not favorable to the growth of the $P$. commune (particularly high temperatures do not favor the growth of this species). Meanwhile, we observed that the population of the A. flavus species is relatively large in the Bolesław shaft, when compared to its size in other shafts. Finding a significant interaction between the fungal species and the parts of each shaft let us confirm that more fungi occurred in the timber storage areas of the shafts Bolesław and Lubin West than beside the conveyor-belt system of the Lubin Main shaft. Also, many more fungal colonies were collected in the pump room of the Main shaft than in the so-called air split of the West shaft.

The relationship between the type of shaft and the sampling point on the one hand, and the population size of the fungal species on the other, are discussed below, where the correspondence plots of the fungal response to the analyzed factors represent the data in two dimensions, displaying the full information on the interactions among the shafts (Fig. 1).

If we look at the two-dimensional position of each species in the plot, we can identify three groups of fungi with different population sizes, depending on shaft and sample collection point. The first group involves $P$.

Table 3. Fungal populations in various parts of Lubin West shaft $\left(\mathrm{CFU} / \mathrm{m}^{3}\right)$.

\begin{tabular}{lrrrrrrr}
\hline & \multicolumn{3}{c}{ Parts of Lubin West Shaft } \\
\cline { 2 - 8 } Fungi & $\begin{array}{c}\text { Timber } \\
\text { Storage }\end{array}$ & $\begin{array}{c}\text { Transfer } \\
\text { Point }\end{array}$ & $\begin{array}{c}\text { Dump } \\
\text { Hopper }\end{array}$ & $\begin{array}{c}\text { Air } \\
\text { Split }\end{array}$ & $\begin{array}{c}\text { Machine } \\
\text { Chamber }\end{array}$ & Mouth & Total \\
\hline Aspergillus flavus & 740 & 1580 & 60 & 2 & 0 & 0 & 2382 \\
Aspergillus niger & 60 & 200 & 1 & 40 & 1 & 1 & 303 \\
Botrytis cinerea & 1 & 0 & 0 & 1 & 0 & 0 & 2 \\
Penicillium citrinum & 0 & 560 & 1 & 0 & 40 & 140 & 741 \\
Penicillium commune & 0 & 1 & 0 & 0 & 0 & 0 & 1 \\
Penicillium expansum & 1220 & 840 & 40 & 1 & 0 & 60 & 2161 \\
Penicillium luteum & 560 & 0 & 1 & 1 & 0 & 0 & 562 \\
Penicillium notatum & 7780 & 780 & 40 & 60 & 80 & 220 & 8960 \\
Penicillium urticae & 5340 & 2520 & 60 & 100 & 0 & 20 & 8040 \\
Penicillium vermiculatum & 720 & 1180 & 60 & 260 & 1 & 1 & 2222 \\
Penicillium waksmani & 3300 & 0 & 40 & 80 & 60 & 100 & 3580 \\
Total & 19721 & 7661 & 303 & 545 & 182 & 542 & 28954 \\
\hline
\end{tabular}


W. Pusz, W. Kita, And R. Weber

Table 4. Fungal populations in various parts of Lubin Main shaft $\left(\mathrm{CFU} / \mathrm{m}^{3}\right)$.

\begin{tabular}{lcccccrrr}
\hline & \multicolumn{5}{c}{ Parts of Lubin Main Shaft } \\
\cline { 2 - 8 } Fungi & $\begin{array}{c}\text { Belt } \\
\text { Conveyor }\end{array}$ & $\begin{array}{c}\text { Foreman's } \\
\text { Office }\end{array}$ & $\begin{array}{c}\text { Dump } \\
\text { Hopper }\end{array}$ & $\begin{array}{c}\text { Main pump } \\
\text { Room }\end{array}$ & $\begin{array}{c}\text { Machine } \\
\text { Chamber }\end{array}$ & Mouth & Total \\
\hline Aspergillus flavus & 0 & 100 & 0 & 0 & 1 & 1 & 102 \\
Aspergillus niger & 0 & 60 & 0 & 1 & 0 & 1 & 62 \\
Botrytis cinerea & 80 & 4 & 80 & 0 & 20 & 1 & 185 \\
Penicillium citrinum & 120 & 40 & 1 & 560 & 0 & 200 & 921 \\
Penicillium commune & 180 & 0 & 300 & 560 & 0 & 0 & 1040 \\
Penicillium expansum & 1 & 0 & 0 & 1 & 0 & 40 & 42 \\
Penicillium luteum & 1 & 1 & 1 & 0 & 0 & 0 & 3 \\
Penicillium notatum & 80 & 1 & 4 & 80 & 0 & 260 & 425 \\
Penicillium urticae & 40 & 100 & 140 & 2240 & 7 & 40 & 2567 \\
Penicillium vermiculatum & 0 & 80 & 100 & 540 & 1 & 0 & 721 \\
Penicillium waksmani & 0 & 40 & 0 & 1080 & 120 & 80 & 1320 \\
Total & 502 & 426 & 626 & 5062 & 149 & 623 & 7388 \\
\hline
\end{tabular}

notatum and $A$. flavus, the second group is formed by $A$. niger, $P$. vermiculatum, $P$. expansum, $P$. luteum, $P$. urticae, and $P$. waksmani and the third group with greater variation in fungal population sizes of Botrytis cinerea, P. citrinum, and $P$. commune. As pictured by the length and direction of the vectors starting at the origin of the coordinate system, each shaft influences the population size of each fungal species in many different ways. The considerable length of the vector associated with the Main shaft indicates that this variable has a considerable discriminating power, which contributes to differentiating the population size of each fungal species. The orthographic projections of the points, which represent the fungal species, onto vectors associated with the variables, confirm the increase in A. flavus and $P$. notatum populations in Bolesław shaft. On the other hand, the position of the point that represents the size variations of the $P$. expansum population suggests that this fungus is well adapted to grow in the climate conditions of the Lubin West shaft. Also, the projection of the point representing the variability of $P$. citrinum, on the extended vector associated with Lubin Main shaft, confirms the increased growth of its population in the Lubin Main shaft conditions.

The second column of Table 5 displays the row masses, which are the total relative frequencies of each row. These can be interpreted as information on the significance of each row (shaft) for the population size variations within the analyzed fungal species. Thus, the climate conditions in Bolesław shaft stimulated the growth of fungal populations to the largest extent, while the conditions in the Main shaft decreased the population sizes of the analyzed species. The

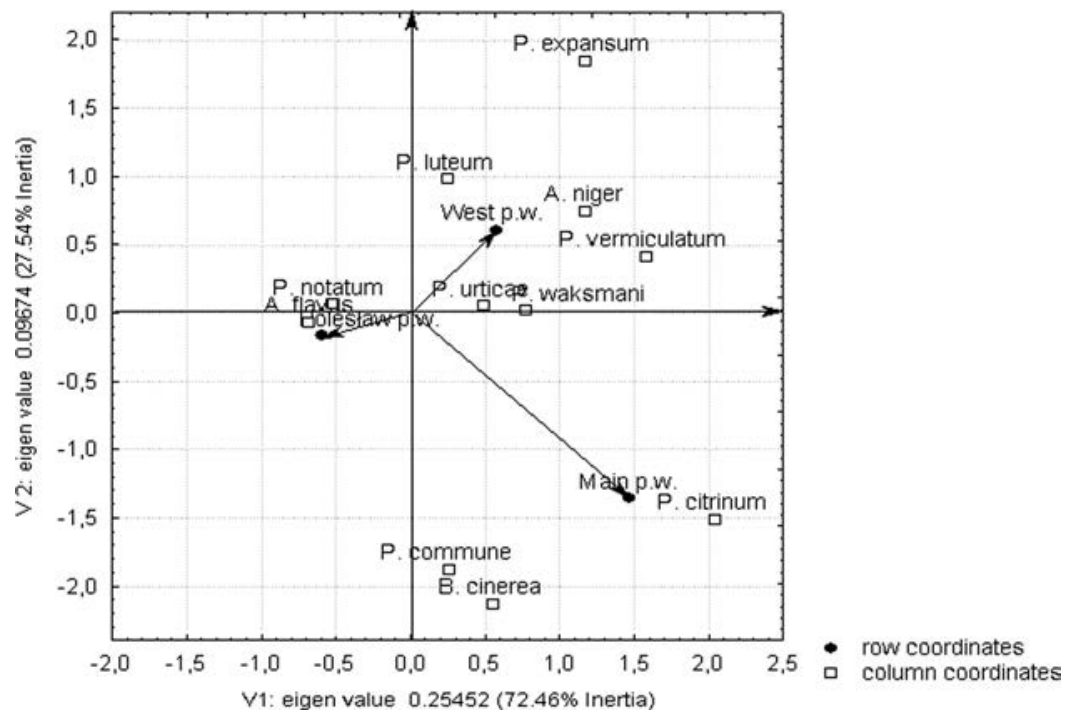

Figure 1. Biplot of population-size variations within the fungal species occurring in different KGHM mine shafts (V1 dimension 1, V2 - dimension 2). Dimensions 1 and 2 show the size of the variation of the number of species of fungi (variance). 
Table 5. Inertia contribution by shaft (Rows).

\begin{tabular}{lccc}
\hline $\begin{array}{l}\text { Intertia Contributions } \\
\text { by Shaft }\end{array}$ & Mass & $\begin{array}{c}\text { Relative } \\
\text { Inertia }\end{array}$ & $\begin{array}{c}\text { Inertia in } \\
\text { Dimension 1 }\end{array}$ \\
\hline Bolesław & 0.560285 & 0.296208 & 0.389829 \\
Lubin West & 0.350325 & 0.281218 & 0.227731 \\
Lubin Main & 0.089390 & 0.422574 & 0.382440 \\
\hline
\end{tabular}

Note: The inertia term is used in correspondence analysis and is analogous to that in terms of variance statistics. Inertia dimension 1 and 2 show the size of the variation of the number of species of fungi (variance).

representation quality of the biplot points determines how precisely each shaft can be evaluated in a space reduced to two dimensions. Values close to 1 indicate that the species have been represented well in the two-dimensional space. Reducing the eleven-dimensional space to a two-dimensional space for the purpose of this experiment still allows for a full presentation of the original variations. The relative inertia of each point shows each variable's absolute contribution to the principal inertia of the original space of eleven dimensions that described the three shafts. The term inertia in correspondence analysis is used by analogy with the definition in physics of moment of inertia, which stands for the integral of mass times the square of the distance to the centroid (Greenacre, 1984). Inertia is defined as the total Pearson Chi-square for the two-way interaction divided by the total sum of the spore numbers of the sampled fungi species.

As suggested by relative inertia values, an increased population size variation within the identified fungal species occurred in Lubin Main shaft. The next columns present the contribution of partial inertia values of the shafts Bolesław, Lubin West, and Lubin Main, to each dimension. The correspondence analysis also allows us to evaluate the similarities among the fungal species and to present them in a space defined by these three shafts. As shown in Table 6 , both the mass value and the relative inertia values in the two dimensions are highest for the $P$. notatum, when compared to other identified fungal species. Thus, we can claim that the $P$. notatum contributed mostly to the size variations within the fungal population in the examined shafts.

\section{Discussion}

A copper-mine environment does not create favorable conditions for the growth of fungal species, and the high concentration of copper compounds, as well as the compounds of other elements, could affect their normal development. Fungi can occur in the soil or in symbiosis with some plants that are capable of growing in such unfavorable conditions (Castro-Silva et al., 2003; Fujii and Fukunaga, 2008; Gibson and Mitchell, 2007). Our research confirms these observations. We found Alternaria alternata spores in the upcast shafts, but not in the mine galleries. Perhaps this species does not find favorable conditions for its growth in the mine. Our research has shown that the most common airborne fungi in the mine are those of the Penicillium and Aspergillus genera. Fujii and Fukunaga (2008) also found these species predominating in coppermine soil in Japan. The work of other researchers surveying copper mines with respect to fungal spores supports these findings (Moharrer et al., 2012). Among the isolated airborne fungal species, the populations of Penicillium notatum, $P$. expansum, and Aspergillus flavus were the most numerous. Piontek and Bednar (2010) obtained similar results, and they claim that these fungi can damage the mining machinery, timber structures, or cables, and, as a consequence, result in serious accidents. Our mycological survey of copper-mine air differs from similar surveys conducted by other researchers in similar mines. A closed gold mine, examined by Ogórek (2012), turned out to host several fungal species, with Trichoderma harzianum, $P$. expansum, and Botrytis cinerea being the most numerous. The results of his study suggest that the spore concentration of Aspergillus and Penicillium fungi could be a health hazard to the miners working in some parts of the mine, especially in those abundant in timber. The mentioned fungal genera (Aspergillus and Penicillium) are believed to

Table 6. Inertia contribution by fungal species (Columns).

\begin{tabular}{lcccc}
\hline Fungal Species & Mass & Relative Inertia & Inertia in Dimension 1 & Inertia in Dimension 2 \\
\hline Aspergillus flavus & 0.144527 & 0.096281 & 0.132044 & 0.002185 \\
Aspergillus niger & 0.004912 & 0.012152 & 0.013403 & 0.008860 \\
Botrytis cinerea & 0.005324 & 0.023762 & 0.003242 & 0.077750 \\
Penicillium citrinum & 0.020629 & 0.164708 & 0.169629 & 0.151762 \\
Penicillium commune & 0.035971 & 0.114969 & 0.004670 & 0.405176 \\
Penicillium expansum & 0.026691 & 0.132466 & 0.071906 & 0.291805 \\
Penicillium luteum & 0.011131 & 0.010491 & 0.001376 & 0.034473 \\
Penicillium notatum & 0.418868 & 0.168344 & 0.230110 & 0.005833 \\
Penicillium urticae & 0.211110 & 0.073696 & 0.100904 & 0.002110 \\
Penicillium vermiculatum & 0.035645 & 0.131304 & 0.173635 & 0.019927 \\
Penicillium waksmani & 0.085192 & 0.071826 & 0.099081 & 0.000118 \\
\hline
\end{tabular}

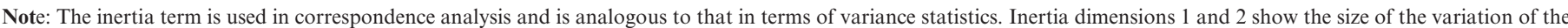
number of species of fungi (variance). 
be an important part of indoor bioaerosols since some of them can produce mycotoxins, which are hazardous to human health (Cabral, 2010). Some of these fungal species can also cause mycoses or other respiratory diseases (Gamboa et al., 1996). Nevertheless, to confirm these results, we would need to perform a series of in vitro or molecular tests, because not all fungal isolates sampled from the atmosphere are able to produce mycotoxins (Ren et al., 1999; Nielsen, 2003).

\section{Conclusions}

The log-linear and correspondence analyses show significant size variations within the fungal populations in each of the copper mine's shafts, as well as in parts of these shafts.

Based on their numbers and abundance, Penicillium notatum and Penicillium urtica turned out to be the fungal species best adapted to grow in a copper-mine environment.

There are significant differences among the shafts and the sample collection points, suggesting a considerable influence of each shaft's microclimate on the population size variations of the identified fungal species. The fungal spore concentrations in the analyzed shafts do not pose a health hazard to miners.

\section{ACKNOWLEDGEMENTS}

We wish to thank to the management staff of KGHM for their acceptance concerning our conducting the research in the mine of the Lubin Mining Company. In particular, our thanks go to the Director of the LMC, Mr. Krzysztof Tkaczuk. We also want to thank Mr Wojciech Sobieszek, the director for safety issues, for his kindness and assistance during our work in the mine. Many thanks go as well to safety inspectors Artur Poniedziałek, Dariusz Mróz, Krzysztof Sokołowski, and Wojciech Wạs. Additionally, we acknowledge the kindness and invaluable hints given to us by all the foremen of the LMC during our underground work. Finally, special thanks go to Ms. Agata Kaczmarek from the Division of Phytopathology and Mycology of the Plant Protection Department at the Wrockaw University of Environmental and Life Sciences for her help in the preparation of the mycological analyses.

\section{REFERENCES}

Cabral, J.P.S., 2010, Can we use indoor fungi as bioindicators of indoor air quality? Historical perspectives and open questions: Science of the Total Environment, v. 408, p. 4285-4295. doi:10.1016/j.scitotenv. 2010.07.005.

Castro-Silva, M.A., Oliveira de Souza Lima, A., Gerchenski, A.V., Jaques, D.B., Rodriguez, A.L., Lima de Souza, P., and Rörig, L.R., 2003, Heavy metal resistance of microorganisms isolated from coal mining environments of Santa Catarina: Brazilian Journal of
Microbiology, v. 34, supplement. 1, p. 45-47. doi:10.1590/S1517-838 22003000500015

Fujii, K., and Fukunaga, S., 2008, Isolation of highly copper-tolerant fungi from the smelter of the Naganobori copper mine, an historic mine in Japan: Journal of Applied Microbiology, v. 105, p. 1851-1857. doi:10.1111/j.1365-2672.2008.03950.x.

Gamboa, P., Jáuregui, I., Urrutia, I., Antépara, I., González, G., and Múgica, V., 1996, Occupational asthma in a coal miner: Thorax, v. 51, p. 867-868. doi:10.1136/thx.51.8.867.

Gibson, R.B., and Mitchell, D.T., 2007, Sensitivity of ericoid mycorrhizal fungi and mycorrhizal Calluna vulgaris to copper mine spoil from Avoca, County Wicklow: Biology and Environment: Proceedings of the Royal Irish Academy, v. 106B, no. 1, p. 9-18.

Goodman, L.A., 1978, Analyzing Qualitative/Categorical Data: LogLinear Models and Latent Structure Analysis: Cambridge, Abt Books, $471 \mathrm{p}$.

Greenacre, M.J., 1984, Theory and Applications of Correspondence Analysis: New York, Academic Press, 364 p.

Grzyb, J., and Frączek, K., 2010, Occurrence of fungal aerosol in overground and underground health resorts: Ecological Chemistry and Engineering A, v. 17, no. 1, p. 73-80.

Heppleston, A.G., and Roodhouse Gloyne, S., 1949, Pulmonary aspergillosis in coal workers: Thorax, v. 4, p. 168-172. doi:10.1136/thx.4.3.168.

Hill, M.O., 1974, Correspondence analysis: a neglected multivariate method: Journal of the Royal Statistical Society C: Applied Statistics, v. 23 , p. $340-354$.

Moharrer, S., Mohammadi, B., Gharamohammadi, R.A., and Yargoli, M., 2012, Biological synthesis of nanoparticles by Aspergillus flavus, isolated from soil of Ahar copper mine: Indian Journal of Science and Technology, v. 5, special issue 3, p. 2443-2444.

Nielsen, K.F., 2003, Mycotoxin production by indoor molds: Fungal Genetics and Biology, v. 39, p. 103-117. doi: 10.1016/S1087-1845(03) 00026-4.

Obtułowicz, K., 2006, Environment and its impact on allergy: Problemy Higieny i Epidemiologii, v. 87, no. 4, p. 359-363.

Ogórek, R., 2012, Mycological air pollutions in Gold Mine (Gertruda's Adit) in Złoty Stok: Proceedings of the 36th Conference of Agricultural Students and Veterinary Medicine with International Participation, Novi Sad (Serbia), v. 36, p. 100-107.

Ogórek, R., Lejman, A., and Matkowski, K., 2013, Fungi isolated from Niedźwiedzia Cave in Kletno (Lower Silesia, Poland): International Journal of Speleology, v. 42, p. 161-166. doi:10.5038/1827-806X.42. 2.9 .

Piontek, M., and Bednar, K., 2010, Biodeteriogenne grzyby w kopalniach węgla kamiennego [Biodeteriogenic molds in coal mines]: Zeszyty Naukowe Uniwersytetu Zielonogórskiego, Inżynieria Środowiska, v. 18 , p. $57-64$.

Polish Norm, 1989a, PN-89/Z-04111/02: Air Purity Protection. Microbiological Testing. Determining the Concentration of Bacteria in the Atmosphere (ambient concentration) by Aspiration and Sedimentation Sampling [In Polish]: Polski Komitet Normalizacji Miar i Jakości (Polish Committee for Measurements and Quality Standards).

Polish Norm, 1989b, PN-89/Z-04111/03: Air Purity Protection. Microbiological testing. Determining the Concentration of Microscopic Fungi in the Atmosphere (ambient concentration) by Aspiration and Sedimentation Sampling [In Polish]: Polski Komitet Normalizacji Miar i Jakości (Polish Committee for Measurements and Quality Standards).

Polish Norm, 2007, PN-EN 13098: Workplace Atmosphere - Guidelines for Measurement of Airborne Micro-organisms and Endotoxins [In Polish], Polski Komitet Normalizacyjny (Polish Committee for Standardization).

Ren, P., Ahearn, D.G., and Crow, S.A., Jr., 1999, Comparative study of Aspergillus mycotoxin production on enriched media and construction material: Journal of Industrial Microbiology and Biotechnology, v. 23, p. 209-213. doi:10.1038/sj.jim.2900721.

Rusca, S., Charrière, N., Droz, P.O., and Oppliger, A., 2008, Effects of bioaerosol exposure on work-related symptoms among Swiss sawmill workers: International Archives of Occupational and Environmental Health, v. 81, p. 415-421. doi:10.1007/s00420-007-0228-6. 